\title{
Improving the Properties of Dental Porcelain Luminescence Using Silicon Carbide
}

\author{
Nima Norouzi ${ }^{1, * \text { (D) }, \text { Zahra Nouri }}{ }^{2}$ (D) \\ 1 School of Energy and Physics, Amirkabir university of technology (Tehran Polytechnic); nima1376@aut.ac.ir (N.N.); \\ 2 School of Medicine, Tehran University of Medical Sciences, Tehran, Iran; zn65133@gmail.com (Z.N.); \\ * Correspondence: nima1376@aut.ac.ir;
}

Received: 8.10.2020; Revised: 8.11.2020; Accepted: 11.11.2020; Published: 15.11.2020

\begin{abstract}
An ideal dental restorative should have the same light reflection, diffusion, and fluorescence properties as a natural tooth. Natural teeth always emit intense blue fluorescence under ultraviolet light, making the teeth look whiter and brighter in daylight. One of the limitations in trying to simulate restorative materials is the unique structure of natural teeth. This study aimed to simulate dental tubules and investigate the effect of different porosity percentages on dental porcelain luminescence properties. In this laboratory study, a control sample (without silicon carbide) and three dental porcelain samples with different percentages of porosity were prepared by adding 1,2,3\% silicon carbide luminescence intensity was examined by spectrophotometer and compared with natural teeth. An increase in luminescence properties was observed with increasing porosity. The highest light intensity was observed in the sample's porosity with $3 \%$ silicon carbide. The lowest intensity was observed in the porosity of the sample with $1 \%$. Creating porosity in dental porcelain reduces refraction, collision, and light reflection. Therefore such specimens will be brighter and more transparent when exposed to ultraviolet light.
\end{abstract}

Keywords: dental porcelain; dental tubules; optical properties; porosity; luminescence.

(C) 2020 by the authors. This article is an open-access article distributed under the terms and conditions of the Creative Commons Attribution (CC BY) license (https://creativecommons.org/licenses/by/4.0/).

\section{Introduction}

For the past two hundred years, amalgam has been the dominant player in the field of dental restorations. However, today, color restorations, mostly made of composites, ceramics, and dental porcelain, have replaced amalgams. The main advantage of color restorations is the issue of beauty. However, the non-use of mercury in amalgam restorations is also one of the advantages of color restorations; Because researchers believe that the mercury in amalgam may cause long-term side effects.

An ideal restorative material should have the same light reflection, emission, and fluorescence properties as natural teeth. Otherwise, their aesthetic quality will be reduced [1]. Due to the importance of beauty, the optical properties, including translucency of ceramic materials in Many studies, have been considered. Semi-transparency of dental materials is generally measured using the semi-transparency parameter and the contrast ratio. Contrast ratio is the ratio between a sample's reflection on a black background compared to a white background with an individual reflection [2]. Studies have shown that thickness indirectly affects the passage of light through dental porcelain. The thicker the material, the lower the translucency [3]. 
Luminescence is the emission of light by matter due to ultraviolet and visible radiation. Ideally, a restorative material should have a luminescence similar to that of natural tooth tissue. Luminescence can be used as a tool to distinguish restorative material that distinguishes it from natural tooth tissue. It is a single excitation state (fluorescence), and long-term emission is a triplet excitation state (phosphorescence). A sample can show fluorescence, phosphorescence, or both [4].

Researchers' study of the effect of fillers' amount and size on composite resin's optical properties has shown that samples' optical properties decrease with increasing the amount and size of filler particles. (5) Nanofillers have better optical properties compared to samples containing microfilters $(7,6)$. Another issue is the technique of filling teeth. To fill teeth, two conventional techniques of layering and one-step filling are used. Research in this field shows the formation of an oxygen barrier layer at the composite-composite interface layer site and increases light scattering due to contact with this layer, and reduces the transparency of the restoration in the layering technique [8].

Decreased optical properties of dental restorations can also be due to the high thickness of the specimens. The high thickness of the restoration, which is unavoidable in many cases, increases the reflection and diffusion of light and reduces the intensity of the transmitted light due to the reduction of the depth of polymerization and the increase of internal collisions [913].

The optical properties of teeth and porcelain include color, semi-transparency, hue, light, and chroma value. The various compounds and the crystallinity of different ceramic systems such as lithium disilicate, fluorapatite, or leucite affect these systems' optical properties. Increasing Crystallinity to Increase Mechanical Strength Increases Opacity [14]. Achieving similar tooth restoration requires two steps: selecting the best possible shade using the shadow guide and reproducing this shade with dental material properly done [15].

Casolco et al. [16] obtained translucent zirconia ceramics measuring $55 \mathrm{~nm}$ using stabilized nanostructured powders. They have suggested that more light passes through the scattering created by the particles' interaction when the grain size is significantly smaller than the wavelength of visible light. The presence of internal fine particles maximizes the translucent material's opacity. The presence of impurities and turbidity conditions such as temperature and time can also significantly affect the particle size and translucency.

Dozic et al. [17] have shown that the porcelain layer's thickness affects the final shade of ceramic restorations. Small changes in the thickness or shade of the translucent porcelain layers have a significant effect on the restoration's shade.

In a paper published by Nakajima et al. [18], a comparison was made between natural cow teeth and three composite resin samples used in the market. The results showed that in natural teeth with increasing thickness; Similar to restorers; There is a decrease in light transmission and transparency, but the light distribution in the teeth, unlike restoratives, decreases with increasing thickness. This difference can be the density, diameter, and orientation of the tubules in the tooth structure.

Examination of the tooth structure shows that the tooth contains microscopic channels called dental tubules, which extend from the nerves of the tooth (pulp) to the outside or enamel of the tooth and contain physiological fluids [19]. In teeth with tubules, The transverse refraction of light is less than the oblique and longitudinal position. Besides, materials inside the tubules (water, air, tooth fluids, or minerals) affect light transmission and transmission and absorption properties [18]. 
This study aimed to simulate dental tubules in dental porcelain specimens and investigate their effect on dental specimens' luminescence properties.

\section{Materials and Methods}

In this experimental study, 16 samples of tablets with a thickness of $2 \mathrm{~mm}$ and a diameter of $5 \mathrm{~mm}$ were prepared to prepare dental porcelain specimens with different percentages of porosity. To prepare the samples, silicon carbide with weight percentages of 1 , 2 , and $3 \%$ was used to create different porosities in the sample and without silicon carbide to make the control sample.

Porcelain powder (Noritake Company, Japan) was used as the predominant phase in these samples. Silicon carbide with a particle size of 40 microns (Sigma-Aldrich, Japan) was used as an additive with $99.8 \%$ purity to create porosity. According to the instructions mentioned in reference (20) and optimization, first distilled water with $5 \%$ by weight of polyethylene glycol (as a binder) was added to a mixture of porcelain powder and silicon carbide, in amounts of 3-0\% by weight and a solution was obtained diluted. (The water-tomixture ratio was 0.8 to $1 \%$ by weight.) The diluted solution was stirred for 30 minutes with a magnetic stirrer and then placed in the oven for 1 to 2 hours. It was then sieved with a 0.3 mesh, and a powder with a particle size of 550 microns was obtained. A dry press pressed the powder with a pressure of $10 \mathrm{MPa}$, and tablets with a thickness of $2 \mathrm{~mm}$, and a diameter of $5 \mathrm{~mm}$ was made. The samples were sintered in a furnace at a rate of increase of $5{ }^{\circ} \mathrm{C} / \mathrm{min}$ until reaching a temperature of $1150{ }^{\circ} \mathrm{C}$ and kept at this temperature for 20 minutes at atmospheric pressure. After leaving the furnace, the samples were subjected to scanning electron microscopy (SEM), $\mathrm{X}$-ray diffraction (XRD), and then spectrophotometry.

A healthy anterior tooth of a 27-year-old man broken in an accident was used to prepare a dental sample. Dental incisions in different thicknesses can be limited to enamel or dentin and form a combination of enamel and dentin. To make the incision, the teeth were molded into the resin. Then incisions were made in the vertical direction with a thickness of $2 \mathrm{~mm}$.

\section{Results and Discussion}

Figure 1 shows the XRD pattern of a $2 \%$ by weight silicon carbide sample after sintering at $1150{ }^{\circ} \mathrm{C}$. As can be seen in this diagram, silicon carbide is not seen in the sample sintering. However, silicon is present as $\mathrm{SiO}_{2}$ in the structure. The results show that after sintering, $\mathrm{SiC}$ is oxidized to $\mathrm{SiO}_{2}, \mathrm{CO}_{2}$. The formation of the $\mathrm{SiO}_{2}$ protective layer on the surface occurred due to the air atmosphere's process. Figures 2 (A, B, and C) show the results of SEM analysis of samples with a percentage of silicon carbide of 1 to $3 \%$.

According to SEM images, an increase in porosity can be seen due to the increase in silicon carbide at $1150{ }^{\circ} \mathrm{C}$. In $1 \%$ silicon carbide, due to the low carbon structure, the volume of $\mathrm{CO} 2$ gas due to oxidation is low, resulting in very small spherical porosities. In general, the porosity created by this method is isolated and discontinuous, and, due to the high viscosity of the liquid phase, can not be removed from the structure (Figure 2-A). The average size of the porosity does not exceed 100 microns. In the amount of $2 \%$ silicon carbide, more gas is created than in the first case due to the increase in the volume of carbon. More continuous porosities are created, the size of which is 120 micrometers (Figure 2-B). In the third case, with $3 \%$ silicon carbide, an enormous volume of $\mathrm{CO}_{2}$ gas is created in the structure, which causes interconnected and large porosity (Figure 2-C). In this case, the size of the pores has increased 
to 170 micrometers. In fact, as the percentage of silicon carbide increases, the volume of gas produced increases, and the interconnection of these gases creates larger pores.

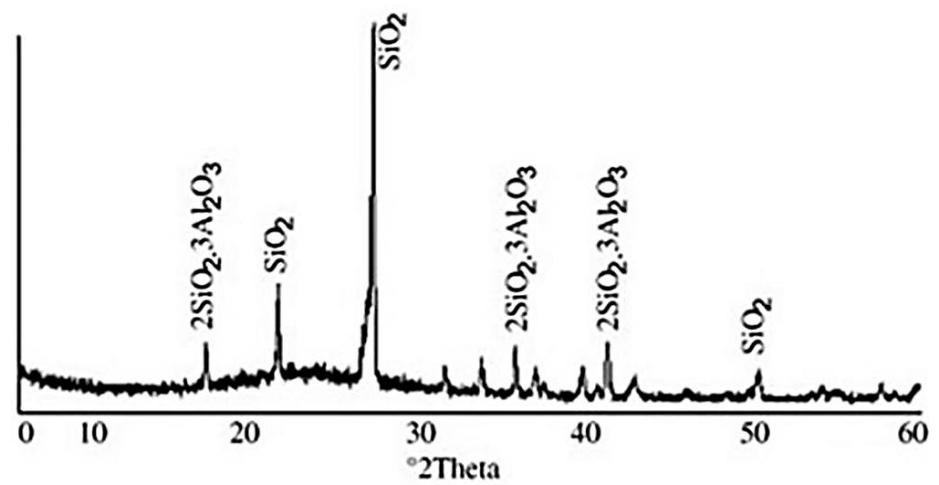

Figure 1. XRD pattern of porcelain sample with $2 \%$ by weight silicon carbide after sintering at $1150{ }^{\circ} \mathrm{C}$

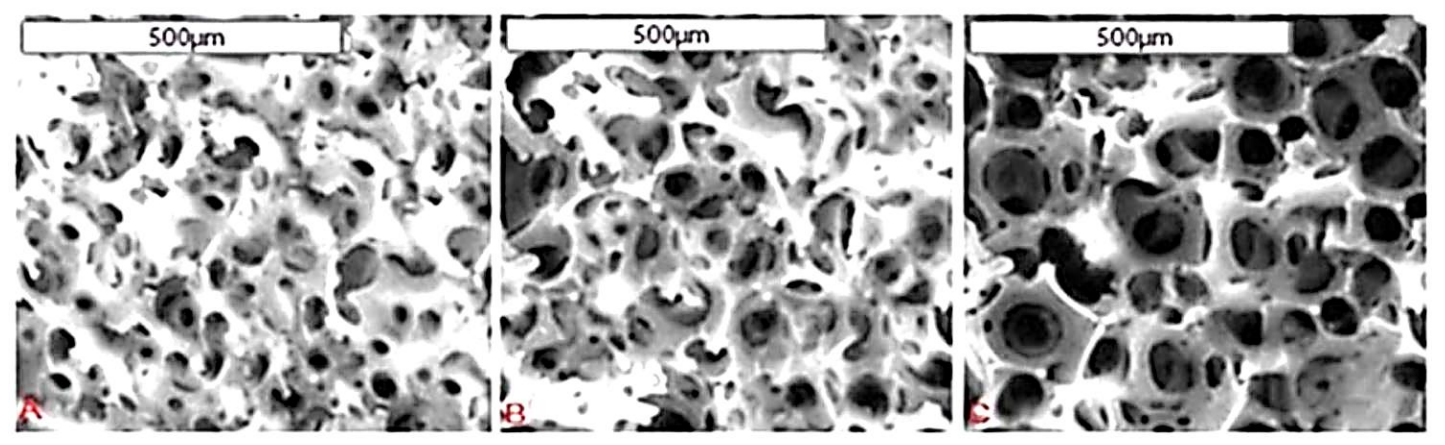

Figure 2. A) $1 \%$ sample, B) $2 \%$ sample, C) $3 \%$ silicon carbide sample.

Figure 3 shows the impact of silicon carbide on the porosity size for samples sintered at 1150 for 20 minutes. Under the same conditions, samples with $3 \%$ silicon carbide have the highest porosity, and samples with $1 \%$ silicon carbide have the lowest porosity. With the increasing amount of silicon carbide in the structure, the pores' size has increased significantly in 2 to $3 \%$.

Figure 4 shows the results obtained by light spectroscopy on each of the four dental porcelain specimens and the natural tooth specimens with a different porosity percentage. The structure of natural teeth in the area of enamel and dentin is almost similar and contains $30 \%$ of minerals (inorganic including proteins) and water and $70 \%$ of hydroxyapatite $\mathrm{Ca}_{10}\left(\mathrm{PO}_{4}\right)_{6}(\mathrm{OH})_{2}$ in terms of weight and $55 \%$ and $45 \%$ of The opinion is voluminous.

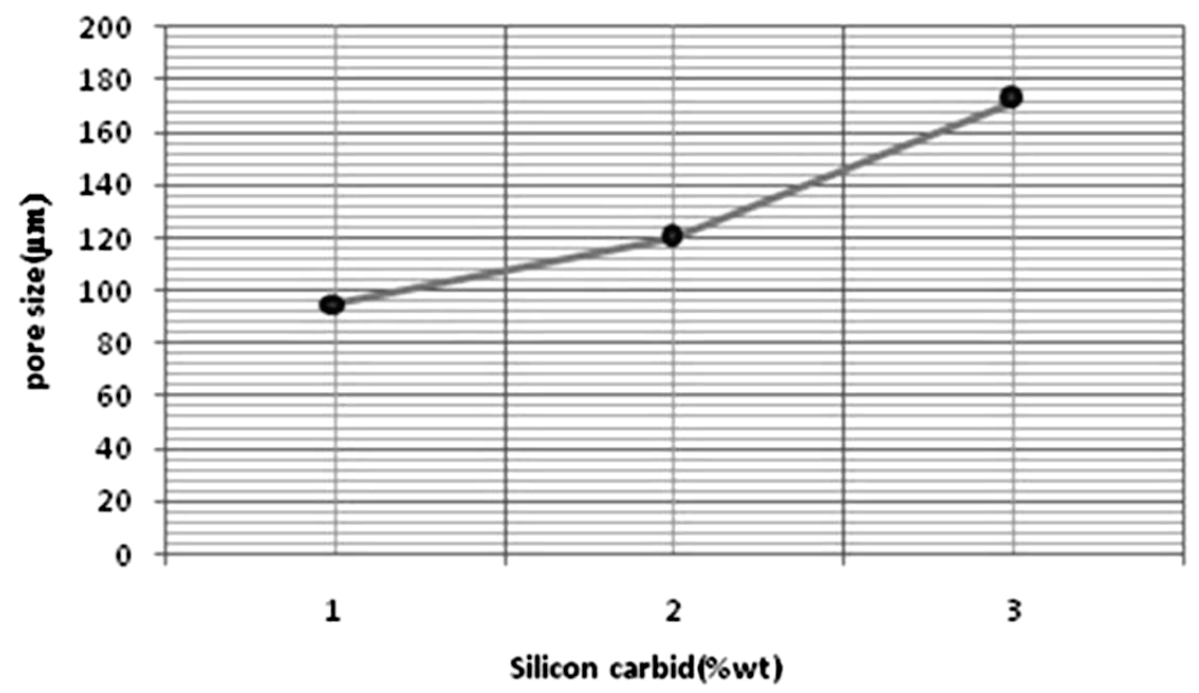

Figure 3. Effect of the amount of silicon carbide in the structure on the size of the pores. 
As shown in Figure 4, photon emission intensity increased with increasing porosity compared to each other and with the control sample and approached the natural tooth. As silicon carbide increases in the structure, porosity is created. The intensity of photons reaching the photocell increases. The difference between the control sample and the sample with silicon carbide confirms this. At higher percentages of silicon carbide, the photons' intensity has increased. It is closer to the natural tooth, which indicates the appropriate effect of interconnected porosity in dental porcelain on its luminescence properties.
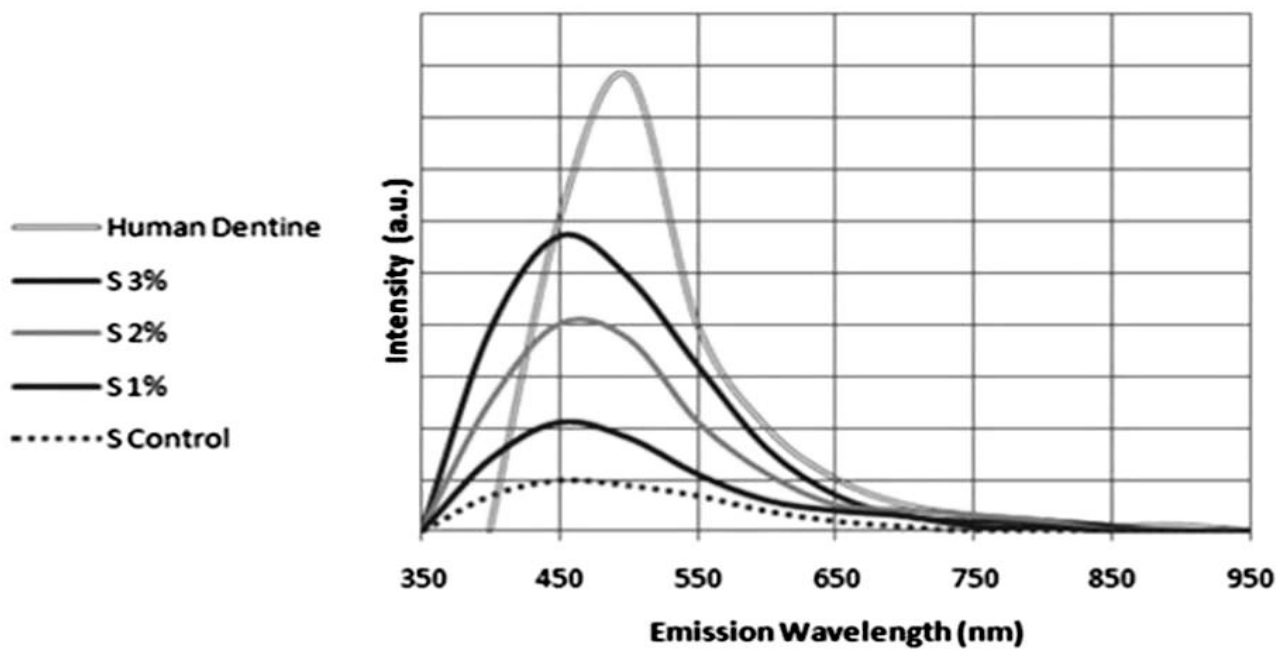

Figure 4. Comparative spectrophotometer for natural teeth and porcelain specimens.

This study aimed to investigate the effect of porosity in dental plaque on its optical properties and luminescence, which are in good agreement with other researchers' results [2127]. The physical properties of porcelain that lead to light absorption can affect the ceramic's optical parameters, such as translucency [26, 28]. A substance consisting of fine particles (approximately $0.1 \mathrm{~mm}$ in diameter) has a lower norm, while larger particles (approximately $10 \mathrm{~mm}$ in diameter) result in surface reflection after light impact, light refraction when passing through, and light absorption [21, 29]. Ceramics with a lower crystalline phase are generally translucent. Zhang et al. [22] reported that the semi-transparency of ceramics containing the crystalline phase is $55 \%$ lower than that of porcelain without the crystalline phase. Simultaneously, crystalline phases have less effect on porosity semi-transparency than porosity, which indicates the importance of porosity on the optical properties of porcelain, which is in good agreement with the results of this study [20-29].

Figueiredo et al. [23] studied three commercial composite resin samples. They showed that resin samples emit different wavelengths with varying intensities depending on the sample type and radiation wavelength. However, all of them emit peaks between 380. They have up to $480 \mathrm{~nm}$. These values were in line with the Lutskaya study [24-26], which was performed on several patients of different age groups and several common restorative materials. According to the results of spectrophotometry, increasing the number of minerals in the samples caused the results to shift to longer wavelengths [26,27]. Dental restorators, which included composite resins and ionomer glass, emitted the most fluorescence at a wavelength of $450 \mathrm{~nm}$, compared to dentures, including low-mineral dentin and enamel, dentin and enamel. High minerals, enriched teeth, samples were taken from young patients, and samples were taken from older patients, low mineral Enamel and enriched Enamel shifted from 450 to $550 \mathrm{~nm}$; however, the intensity of the radiation is greatly reduced, which indicates the great effect of the mineral 
compounds of the teeth on the emitted wavelength and the intensity of the radiation. In other words, mineralized dental specimens have peaks at higher wavelengths [25].

In the present study, intra-structural porosity was created by adding $\mathrm{SiC}$ to dental porcelain specimens. As more and more continuous porosity in the structure increases, the necessary space is created for the photons to move and leave the structure [28]. As shown in Figure 4, high percentages of porosity increase the intensity of the emitted photons. In all studies, dental materials whose spectrophotometry was performed during the daylight wavelength have a peak at a distance of 400 to $500 \mathrm{~nm}$ [19]. These values depend on the manufacturer and the selected color of the restorative material [21]. Spectrophotometric results for porcelain samples in this study showed that all samples had the highest intensity at approximately $450 \mathrm{~nm}$. Their transparency gradually decreased at longer wavelengths and very low at wavelengths above $600 \mathrm{~nm}$ [26]. The peak diffusion intensity was observed for natural teeth at 470 wavelengths and for samples at $450 \mathrm{~nm}$ [27]. At 450 to 650 wavelengths, natural tooth fluorescence is higher and more intense than all-porcelain specimens. It is approximately similar at wavelengths above $650 \mathrm{~nm}$ [25].

The results obtained from spectrophotometry are also consistent with the Lutskaya study [24]. Similarly, the presence of more minerals in the structure caused the radiation wavelength shift in the dental sample compared to the restorative samples. However, in general, the increase in porosity in the restorative material structure has increased the intensity of diffusion. It has brought the transparency of porcelain closer to the transparency of natural teeth. The propagation wavelength range is the same for fabricated and natural teeth. However, differences in the crystal structure, natural tooth composition, tubule orientation, and physiological fluids in the dental tubules have caused diffusion wavelength shifts [25, 29].

\section{Conclusions}

This study has shown that with increased porosity in the porcelain structure, the transparency of the sample increases, and it approaches the natural tooth. However, due to the difference in the structural composition of the shift of about $20 \mathrm{~nm}$ in the peak intensity of dental fluorescence relative to porcelain is observed, which, although not negligible, is acceptable because the teeth and porcelain are in the same wavelength range. The presence of porosity in the structure of the filler material causes the freedom of movement of photons, reduces the internal collisions of photons, and increases the intensity of output photons due to the sample's transparency. In this study, to simulate these dental tubules, controlled porosity was created in the porcelain structure, which improves the optical properties of this dental material, which can be very promising for cosmetic restoration applications.

\section{Funding}

This research received no external funding.

\section{Acknowledgments}

The authors of the article consider it necessary to thank the Campus of New Sciences and Technologies of Tehran University and the Bioceramics Laboratory of the Amirkabir University of Technology for supporting the present research. 


\section{Conflicts of Interest}

\section{The authors declare no conflict of interest.}

\section{References}

1. Lin, G.S.S.; Ghani, NRNA; Ismail, N.H.; Singbal, K.P.; Yusuff, N.M.M. Polymerization Shrinkage and Degree of Conversion of New Zirconia-Reinforced Rice Husk Nanohybrid Composite. European Journal of Dentistry 2020, 14, 448-455; https://doi.org/10.1055/s-0040-1713951.

2. Suryawanshi, A.S.; Behera, N. Tribological behavior of dental restorative composites in chewable tobacco environment. Proceedings of the Institution of Mechanical Engineers, Part H: Journal of Engineering in Medicine 2020, 234, 1106-1112, https://doi.org/10.1177/0954411920940829.

3. Raorane, D.V.; Chaughule, R.S.; Pednekar, S.R.; Lokur, A. Experimental synthesis of size-controlled TiO2 nanofillers and their possible use as composites in restorative dentistry. The Saudi Dental Journal 2019, 31, 194-203, https://doi.org/10.1016/j.sdentj.2019.01.008.

4. Cidreira Boaro, L.C.; Pereira Lopes, D.; de Souza, A.S.C.; Lie Nakano, E.; Ayala Perez, M.D.; Pfeifer, C.S.; Gonçalves, F. Clinical performance and chemical-physical properties of bulk fill composites resin -a systematic review and meta-analysis. Dental Materials 2019, 35, e249-e264, https://doi.org/10.1016/j.dental.2019.07.007.

5. de Menezes, L.R.; da Silva, E.O. Obtaining and characterizing dental hybrid composites with clay or silica nanoparticles and boron-aluminum-silicate glass microparticles. Polímeros 2019, 29, https://doi.org/10.1590/0104-1428.01416.

6. Ritto, F.P.; da Silva, E.M.; Sampaio-Filho, H.R.; Lacerda, R.A.; Borges, M.A.P.; Bastian, F.L. Physicalmechanical evaluation of a microhybrid and a nanofilled composite light activated by quartz-halogen tungsten and light-emitting diode. Journal of Composite Materials 2018, 53, 981-990, https://doi.org/10.1177/0021998318793720.

7. Kinga, B.; Agata, S.; Michal, K.; Jerzy, S. The influence of filler amount on selected properties of new experimental resin dental composite. Open Chemistry 2018, 16, 905-911, https://doi.org/10.1515/chem2018-0090.

8. Alzraikat, H.; Burrow, M.F.; Maghaireh, G.A.; Taha, N.A. Nanofilled Resin Composite Properties and Clinical Performance: A Review. Operative Dentistry 2018, 43, E173-E190,https://doi.org/10.2341/17-208$\mathrm{T}$.

9. Alajely, M.S. Synthesis and characterizations of new dental composites using calciumfluoro aluminosilicate glass. Open Access Journal of Science 2018, 2, https://doi.org/10.15406/oajs.2018.02.00064.

10. de Almeida Salema, C.F.B.; de Barros Silva, P.G.; da Costa Oliveira, P.M.; Lima, J.P.M.; da Silva, R.H.A.; Nobre, T.F.G.; Bezerra, T.P. Forensic study of mechanical properties of dental restoration after burial in mangrove environment. Forensic Science International 2020, 308, https://doi.org/10.1016/j.forsciint.2020.110166.

11. Piccoli, Y.B.; Lima, V.P.; Basso, G.R.; Salgado, V.E.; Lima, G.S.; Moraes, R.R. Optical Stability of Hightranslucency Resin-based Composites. Operative Dentistry 2019, 44, 536-544, https://doi.org/10.2341/18025-L.

12. Liang, J.; Peng, X.; Zhou, X.; Zou, J.; Cheng, L. Emerging Applications of Drug Delivery Systems in Oral Infectious Diseases Prevention and Treatment. Molecules 2020, 25, https://doi.org/10.3390/molecules25030516.

13. Islam, M.T.; Dominguez, A.; Alvarado-Tenorio, B.; Bernal, R.A.; Montes, M.O.; Noveron, J.C. SucroseMediated Fast Synthesis of Zinc Oxide Nanoparticles for the Photocatalytic Degradation of Organic Pollutants in Water. ACS Omega 2019, 4, 6560-6572, https://doi.org/10.1021/acsomega.9b00023.

14. Shen, Y.-Q.; Zhu, Y.-J.; Chen, F.-F.; Jiang, Y.-Y.; Xiong, Z.-C.; Chen, F. Antibacterial gluey silver-calcium phosphate composites for dentine remineralization. Journal of Materials Chemistry B 2018, 6, 4985-4994, https://doi.org/10.1039/C8TB00881G.

15. Chen, Y.-D.; Ngo, T.H.-B.; Chang, Y.-C.; Lin, D.-J.; Hsu, H.-C. Emission spectra of hexagonal zinc oxide microrods due to resonant modes. Journal of the Optical Society of America B 2018, 35, https://doi.org/10.1364/JOSAB.35.002228.

16. Kim, J.H.; Joshi, M.K.; Lee, J.; Park, C.H.; Kim, C.S. Polydopamine-assisted immobilization of hierarchical zinc oxide nanostructures on electrospun nanofibrous membrane for photocatalysis and antimicrobial activity. Journal of Colloid and Interface Science 2018, 513, 566-574, https://doi.org/10.1016/j.jcis.2017.11.061.

17. Chen, S.; Yang, J.; Jia, Y.-G.; Lu, B.; Ren, L.; A Study of 3D-Printable Reinforced Composite Resin: PMMA Modified with Silver Nanoparticles Loaded Cellulose Nanocrystal. Materials 2018, 11, https://doi.org/10.3390/ma11122444.

18. Brandão, N.L.; Portela, M.B.; Maia, L.C.; Antônio, A.; e Silva, V.L.M.; da Silva, E.M.; Model resin composites incorporating ZnO-NP: activity against S. mutans and physicochemical properties characterization. Journal of Applied Oral Science 2018, 26, https://doi.org/10.1590/1678-7757-2017-0270. 
19. Stencel, R.; Kasperski, J.; Pakieła, W.; Mertas, A.; Bobela, E.; Barszczewska-Rybarek, I.; Chladek, G. Properties of Experimental Dental Composites Containing Antibacterial Silver-Releasing Filler. Materials 2018, 11, https://doi.org/10.3390/ma11061031.

20. Rout, S.; Qi, Z.; Petrosyan, L.S.; Shahbazyan, T.V.; Biener, M.M.; Bonner, C.E.; Noginov, M.A. Effect of Random Nanostructured Metallic Environments on Spontaneous Emission of HITC Dye. Nanomaterials 2020, 10, https://doi.org/10.3390/nano10112135.

21. Graeff, R.; Guedes, A.; Quintana, R.; Wendt-Hornickle, E.; Baldo, C.; Walseth, T.; O’Grady, S.; Kannan, M. Novel Pathway of Adenosine Generation in the Lungs from NAD+: Relevance to Allergic Airway Disease. Molecules 2020, 25, https://doi.org/10.3390/molecules25214966.

22. Imai, Y. Generation of Circularly Polarized Luminescence by Symmetry Breaking. Symmetry 2020, 12, https://doi.org/10.3390/sym12111786.

23. Gudkov, S.V.; Penkov, N.V.; Baimler, I.V.; Lyakhov, G.A.; Pustovoy, V.I.; Simakin, A.V.; Sarimov, R.M.; Scherbakov, I.A. Effect of Mechanical Shaking on the Physicochemical Properties of Aqueous Solutions. International Journal of Molecular Sciences 2020, 21, https://doi.org/10.3390/ijms21218033.

24. Ortensi, L.; Vitali, T.; Bonfiglioli, R.; Grande, F. New Tricks in the Preparation Design for Prosthetic Ceramic Laminate Veeners. Prosthesis 2019, 1, 29-40, https://doi.org/10.3390/prosthesis1010005.

25. Jin, S.; Choi, J.-W.; Jeong, C.-M.; Huh, J.-B.; Lee, S.-H.; Lee, H.; Yun, M.-J. Evaluating the Wear of Resin Teeth by Different Opposing Restorative Materials. Materials 2019, 12, https://doi.org/10.3390/ma12223684.

26. Al Moaleem, M.M.; AlSanosy, R.; Al Ahmari, N.M.; Shariff, M.; Alshadidi, A.A.; Alhazmi, H.A.; Khalid, A. Effects of Khat on Surface Roughness and Color of Feldspathic and Zirconia Porcelain Materials under Simulated Oral Cavity Conditions. Medicina 2020, 56, https://doi.org/10.3390/medicina56050234.

27. Barro, Ó.; Arias-González, F.; Lusquiños, F.; Comesaña, R.; del Val, J.; Riveiro, A.; Badaoui, A.; GómezBaño, F.; Pou, J. Effect of Four Manufacturing Techniques (Casting, Laser Directed Energy Deposition, Milling and Selective Laser Melting) on Microstructural, Mechanical and Electrochemical Properties of Co$\mathrm{Cr}$ Dental Alloys, Before and After PFM Firing Process. Metals 2020, 10, https://doi.org/10.3390/met10101291.

28. Han, X.; Sawada, T.; Schille, C.; Schweizer, E.; Scheideler, L.; Geis-Gerstorfer, J.; Rupp, F.; Spintzyk, S. Comparative Analysis of Mechanical Properties and Metal-Ceramic Bond Strength of Co-Cr Dental Alloy Fabricated by Different Manufacturing Processes. Materials 2018, 11, https://doi.org/10.3390/ma11101801. 